\title{
Giving Children a Choice: A Proposal for Developing Empathy
}

\author{
Jeremy Sloan \\ Uniontown, Pennsylvania
}

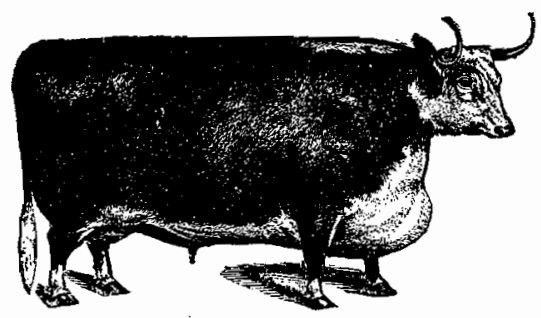

We tend to act upon what we believe to be true. When we deal with the world, we do so in a way which reflects our view of the world. This view has largely been transmitted to us by those who have cared for us as children. Our parents and guardians have shared with us a great deal of information including, to some degree, our methods for dealing with other sentient beings, both human and nonhuman.

As we matured, we were faced with the moral problem of animal exploitation. For most of us, this problem appeared long after we had begun to use animals in everyday life. We were not given the information with which to make a rational decision regarding the treatment of nonhumans. We found this information later in life. As a society, we do not provide children with the information necessary to later make rational choices regarding the treatment of animals. We do not give children an opportunity to empathize with nonhumans.

Before we continue, we should define a few basic terms. I will use the terms 'human' and 'person' more or less interchangeably to refer to rational persons and those who will become rational persons. I will use the words 'animal' and 'nonhuman' to refer to members

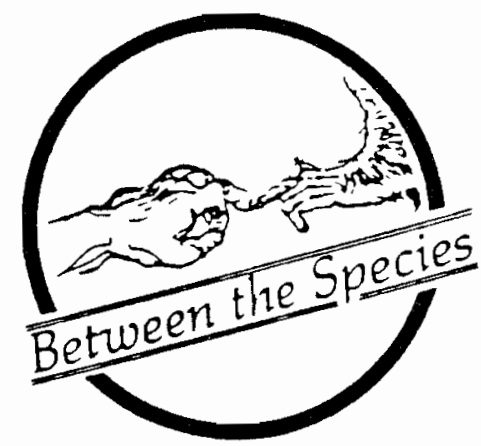

of those species other than human. 'Empathy' has referred and will refer to the act of imagining the experiences, thoughts, and emotions of another from the other's point of view. A 'dynamic agent' will denote a being which makes decisions affecting its own existence.

Our basic social skills are transmitted to us by those who care for us before we begin to make our own moral and interpersonal decisions. According to Jean Piaget, this ability begins to manifest itself between the ages of seven and twelve, during which children reach a state of concrete operations, a state in which a consistent view of life events begins to emerge (Papalia 24). The ability to make these decisions becomes more refined as children mature and reach a stage of formal operations, [learn to deal with abstracts as well as concrete situations] (24). Research consistently shows that children recognize [and usually imitate] the social norms of their communities. Proponents of both social learning theories and cognitive development theories agree on this point.

The social learning theory, which emphasizes that children are encouraged to imitate adult behaviors, provides us with strong evidence to suggest that children do in fact imitate these behaviors. What is most interesting, perhaps, is that children seem to imitate behaviors which give no direct benefit to them (Bandura 589-95). Imitation without direct benefit seems to imply

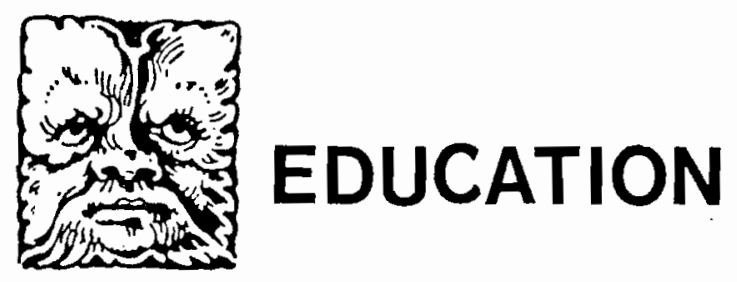


that children gain some indirect benefit from mimicking the actions of their guardians.

The cognitive developmentalist stresses the role of understanding to behavior in children. According to the tenets of this view, children want to become dynamic agents in their own lives. They gain understanding of adult thought processes by imitating adult actions. They become dynamic agents in part by imitating these adult behaviors and demonstrating their new found competence to the community (Gleitman 406-07).

Unfortunately, the desire to be 'grown-up' can lead to problems. The desire to imitate adult behaviors is ingrained before the child is able to consider the reasons for this desire. [To the cognitive developmentalist, the former entails the latter]. Put simply, children attempt to imitate rational behavior before they themselves are rational creatures. Six year-old Jane may envy the fact that her older sister can drive a car, but Jane might not consider that she herself cannot even reach the pedals. If Jane should decide to drive the family car, there will be trouble.

Another major disadvantage of this tendency to imitate is that children learn both desirable and undesirable behaviors. How often have we found that the children around us imitate our bad habits? Some children return from family gatherings with "colorful phrases' which their parents had never intended for them to hear. These phrases have an effect, when spoken by an adult, upon an adult audience. Children quickly find that they can also produce noticeable results by using these phrases on an adult audience. Many an embarrassed parent would agree that a noticeable result is not always a desirable result.

This tendency has consequences far outreaching the trivial. Imitation may be a vital factor in cases of sexual abuse. According to studies conducted by P. K. Trickett and E. J. Susman, many abusers were abused as children (274). These persons have learned a tool for interpersonal relationships which, unfortunately, has lead them to perpetuate a cycle of abuse.

On a more positive note, imitation can also be a factor which promotes beneficial social skills later in life. If the imitation of negative factors leads to the development of negative personality traits, it would seem safe to assume that imitation of some positive factors might lead to the development of positive personality traits. Early education emphasizes interpersonal skills, including cooperation, sharing and empathy. In a 1989 poll, researchers found that parents ranked "sympathy, empathy, [and] concern for others" as one of the top three ideal goals of a preschool environment (Papalia 205). Certainly, these are noble goals, but which beings does the term 'others' include?

Do we even allow most children to consider animals as targets for empathy? Rarely. Do we permit ourselves, as a whole, to consider nonhumans as beings which may have 'human' experiences? Rarely. And when we do concede that nonhumans have similarities to humans, do we accentuate these similarities? Almost never.

Both the 'moral point of view' and the utilitarian viewpoint require a developed sense of empathy (Pluhar). Our ability to recognize suffering in other beings and respond to this suffering stems from our ability to place ourselves into the situation of another being. There can be no true recognition of suffering, in others, without a previous experience of suffering in self. Likewise, there can be no true recognition of pleasure, in others, without a previous experience of pleasure in self.

The suffering which humans have caused to nonhuman animals has in part arisen from an inability, or at least an unwillingness, to empathize with animals. The Cartesians justified vivisection on the grounds that the animals they were vivisecting did not truly feel pain (14). To hold such a view, the Cartesians were forced to deny the evidence of their senses, forced to deny themselves the experience of empathy. A cry of pain, by a dog, is recognizable as such even to a small child. Had a Cartesian allowed himself a dog's point of view, he would have looked at vivisection very differently.

We humans prefer to separate ourselves from the animals which we exploit. Ronald McDonald doesn't carry around a butcher's knife or a cattle prod on television. Frank Perdue has dedicated himself to the proposition that consumers need not remember that they are eating animals. This February, an issue of People magazine featured a full-page Perdue ad extolling the virtues of skinless, boneless poultry products. As the caption reads, there is "no dis-assembly required" (44). Funny, I had always thought the word for separating skin from flesh and flesh from bone was 'dissection.'

Cartoons and illustrations almost always replace live animals in food advertisements, especially if the advertisements involve a suggestion of killing. Few people could describe, with any accuracy, the behavior of a mink living in the wild. You may find, as I have, that most popular uses of the word 'mink' are followed by the word 'coat' or 'stole.' Even pesticide 
commercials and advertisements caricaturize insects as being deliberately malicious. How easy to kill a rat terrorizing your loved ones, how much harder to kill an animal building itself a home.

In each of the above cases, the advertiser has tried to distance the consumer from any chance to empathize with an animal's suffering. Slaughterhouse films simply do not sell cheeseburgers. These observations may seem obvious, but they become important considerations when we want to encourage empathy with nonhuman animals.

Our exposure to dead animals comes mostly in the form of food and clothing. As a species, we see most living animals as unfinished products-products which we finish by killing and then processing. Animals become a function of how we may use or dispose of them. Unfortunately, most children mature exposed to such a situation. Many of us were raised in such a situation.

Western civilization goes to great lengths to divorce the experiences of being a human from the experiences of being a nonhuman. Separation of human and nonhuman is intrinsic among some of the words with which humans describe that which is distasteful to us. Such slurs often attack the intelligence of the target. The names of nonhuman animals commonly describe qualities which we do not admire in human individuals. Take, for example the French betise. The word is a derivative of bête, or beast. Taken literally, the word denotes an 'animal' or irrational frame of mind (Collins 27). Betise, translated strictly, means "animalish." In everyday language, the word is a derogatory term comparable to the English "dumbox," or idiot.

Peter Singer has made an important point about the distance we keep from the animals which our civilization eats. In Animal Liberation, he describes the care with which humans change the names of the flesh they eat from the barnyard [or, more likely, factory], to the table. I doubt that many young children have a clear indication of what 'veal' is. 'Ground beef' or, 'hamburger,' has little obvious relationship to the animal from which it comes.

We do call the fleshes of birds and fish by their original names when we serve them as food. However, the experiences of being either an aquatic creature or a bird are not quite as similar to the experiences of being a human as are the experiences of being a landbound mammal.
The extent of our empathy inust depend, in part, upon the extent of the similarities which we recognize between ourselves and other beings. At the very least, those beings with which humans empathize must be sentient. If we do not recognize any similarities, we cannot empathize at all. If our experiences are almost completely alien to those with which we would like to empathize, little rapport with such beings can be made.

It is very difficult, for example, to empathize with an ant. We can recognize shared sensations such as pain, light, and sense of smell, but beyond such basics, we can not truly take the viewpoint of an ant. We can certainly speculate upon experiences foreign to our own, but our speculations will be vague, uncertain.

How are children exposed to animals? What sort of model do we provide for them, so that they might take our example? In most cases, humans are not exposed to living animals at all. At the age of three or four, most children have had little contact with animals, except for contact with house pets. Aside from those animals which we keep as pets, and those which coexist with us on a daily basis [such as rodents, birds and insects], we rarely encounter other species. Those species which we do encounter are likely to be considered "pests," such as flies, rats or roaches. Even those species which do no direct harm to humans, such as sparrows or pigeons, seem annoying to some.

How can a child connect the act of eating meat to the act of killing an animal when the child has little or no exposure to living animals? We shield children from the very existence of the slaughterhouse. Our language and our treatment of those species with which we coexist give little indication, to children, that they are eating things which were once living, breathing creatures.

As I know from personal experience, it is easier to consider eating a 'cheeseburger' than it is to justify eating a piece of 'ground, dead cow covered with fermented cow excretions.'

The conscious recognition of shared experience is almost a synonym for empathy among beings. When this acknowledgment does not occur, empathy cannot occur. When we direct our imagination towards the lives of other species, our empathetic impulses are directly limited by our knowledge of the experiences of these other species.

It should come as no surprise, therefore, that children embrace the thinking which underlies animal exploitation. The shock of discovering oneself a killer 
is considerably lessened by a taste for beef or a fear of spiders. Even more importantly, animals are not seen as beings with which empathy can occur. This mentality, after denying the relationship of human experience to nonhuman experience, takes the following form:

A. Nonhuman beings can be in a combination of four states: living or dead, captive or wild.

B. Nonhumans which are living captives provide either amusement for humans, targets for experimentation, or food.

C. Nonhumans which are both living and wild become a nuisance, a danger, a possible 'product,' a target of 'sport,' or else they exit the scope of human affairs altogether. [While incomplete in an ecological sense, this view is nevertheless popular].

D. Animals which are captive and dead [at least those killed by humans] are a source of food and clothing. At the very least, they are to be discarded as a health threat.

E. Animals which are wild and dead [which would be quite a contradiction if the words were being used differently] have little or no interest to humans other than as a potential source of disease.

Although these premises have numerous pitfalls and inaccuracies when taken, the thinking behind these premises is widespread.

For many, the decision to stop exploiting animals begins with an appeal to empathy. However, as I have mentioned, animals are not something with which we are encouraged to empathize.

In many cases, nonhumans are presented side-byside with the relative advantages and disadvantages which they provide for humans. The Funk \& Wagnalls encyclopedia provides a useful example of this. The word rodent is followed by a definition of about two-hundred words. This definition consists of a biological description, a few sentences which describe rodent habitats, and a description of the ways in which various rodents benefit or harm humans (320-21). Some of the rodents described on these pages sound as if they were being advertised. Others sound as if they should be exterminated from the planet. In the context of this description, the rodent is a function of its usefulness to humanity.

That a rodent is a dynamic agent in its own existence never enters the definition. That a rodent exists independent of human intervention never enters the definition.
Perhaps if we expose children to nonhuman animals earlier, as dynamic beings, with an equitable emphasis upon the similarities between humans and nonhumans, these children will be less likely to dismiss nonhumans as unworthy of any moral consideration. Let us be realistic. At the very least, children will be able to consider animals as beings, and not as products.

We need not try to 'sell' any sort of moral code to children or adolescents in order to increase empathy. We need not try to shock or traumatize children either. We simply need to examine those structures which view animals as products, and insist, in the interest of truthfulness, that such structures be altered to reflect the fact that animals are beings. We cannot expect children to empathize with static objects or products. If we inform our children that an animal's value depends upon its usefulness to humans, our children will treat animals as products. We need to demonstrate that each sentient being has an existence unto itself, more vital than its relationship to humankind.

Granted, to do this will not bring an immediate end to the suffering which humans cause nonhumans. To do this will not bring an immediate change to the way in which most humans view other species. But to do this, ultimately, will be to break down some of the artificial barriers which now separate the human experience of living from the nonhuman experience of living.

\section{Works cited}

Bandura, A. "Influence of Models' Reinforcement Contingencies on the Acquisition of Imitative Responses." Journal of Personality and Social Psychology. I (1965): 589-95.

Gousin, Pierre-Henri. Collins French-English English-French Dictionary. New York: Berkley Books, 1985.

Descartes, Rene. "Animals Are Machines." from Discourse on Method. Reprint. Animal Rights and Human Obligations. eds. Tom Regan and Peter Singer. 2nd ed. New Jersey: Prentice-Hall, 1989.

Gleitman, Henry. Basic Psychology. 2nd ed. New York: W. W. Norton, 1987.

Papalia, Diane E., and Sally Wendkos Olds. Human Development. 5th ed. New York: McGraw-Hill, 1992.

Piuhar, Evelyn. "Philosophy 103: Ethics and social Issues." Lecture materials. Penn State University. Spring 1993. 
Perdue Farms.. Inc. "(no dis-assembly required)." Advertisement.People. (February 8. 1993): 44.

Singer. Peter. Animal Liberation. Random House. Inc.: NY. 1975
Trickett. P. K. and E. J. Susman. "Parental Perceptions of Child-Rearing

Practices in Physically Abusive and Non-abusive Families." Developmental Psychology. 24.2 (1988): 270-76.

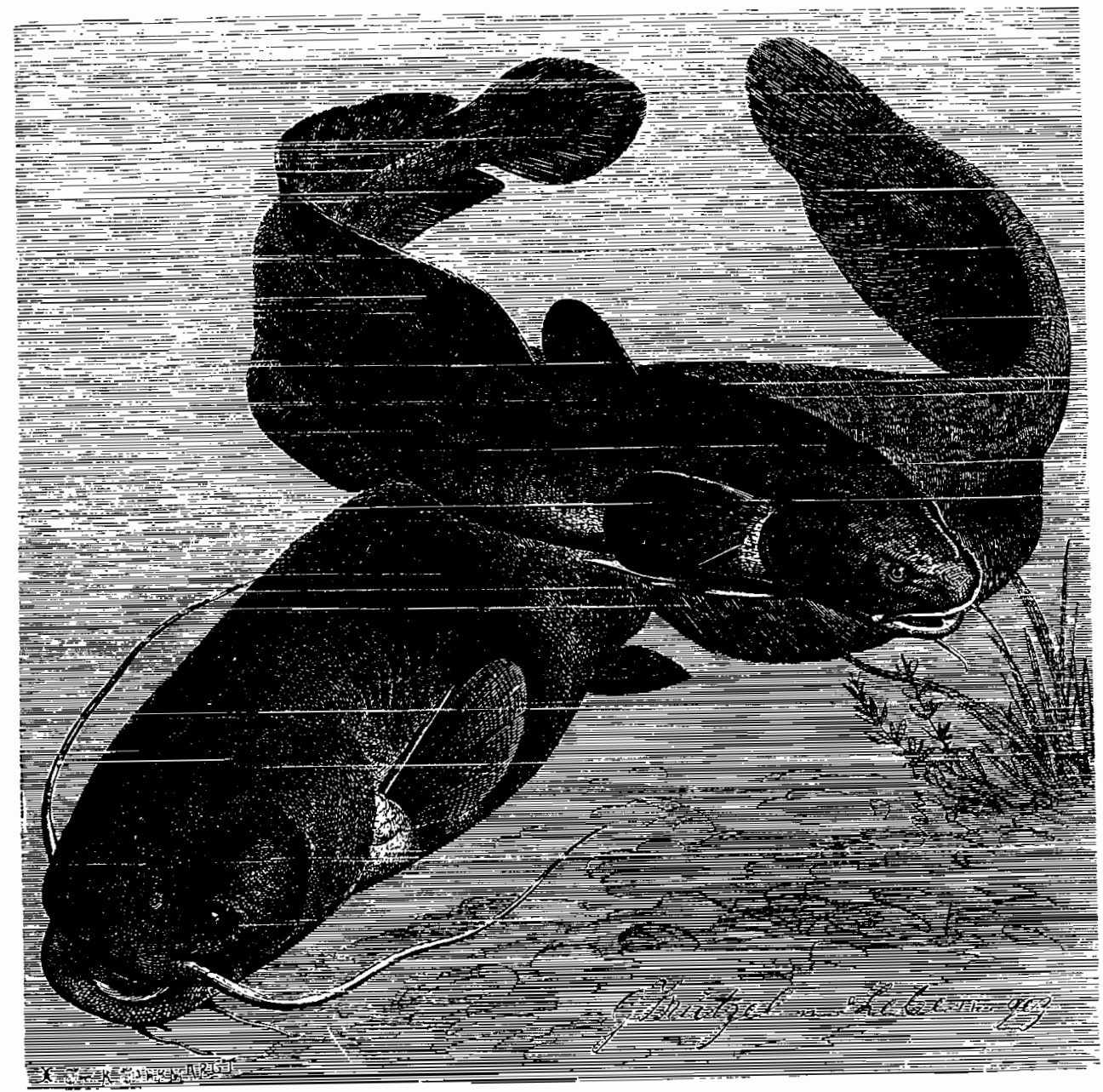

